\title{
Plasma Membrane Cholesterol Regulates the Allosteric Binding of 1-Methyl-4-Phenylpyridinium to Organic Cation Transporter 2 (SLC22A2)
}

\author{
Severin Hörmann, Zhibo Gai, Gerd A. Kullak-Ublick, and Michele Visentin \\ Department of Clinical Pharmacology and Toxicology, University Hospital Zurich, University of Zurich, Switzerland (S.H., \\ Z.G., G.A.K.-U., M.V.); Key Laboratory of Traditional Chinese Medicine for Classical Theory, Ministry of Education, Shandong \\ University of Traditional Chinese Medicine, Jinan, People's Republic of China (Z.G.); and Mechanistic Safety, CMO \& Patient \\ Safety, Global Drug Development, Novartis Pharma, Basel, Switzerland (G.A.K.-U.)
}

Received June 20, 2019; accepted October 11, 2019

\begin{abstract}
The human organic cation transporter 2 (OCT2) mediates the first step of tubular secretion of most positively charged substances. We describe the role of plasma membrane cholesterol in OCT2 activity. Human embryonic kidney 293 cells overexpressing OCT2 (OCT2-HEK293) and wild-type HEK293 cells (WTHEK293) were employed. Cellular cholesterol content, assessed by thin layer chromatography, was manipulated using empty methyl- $\beta$-cyclodextrin $(\mathrm{m} \beta \mathrm{cd}$ ) and cholesterol-presaturated $\mathrm{m} \beta \mathrm{cd}$ (RAMEB). The effect of $\mathrm{m} \beta \mathrm{cd}$ on OCT2 protein stability and oligomerization state was evaluated by immunofluorescence and Western blotting. Transport activity of OCT2 was measured using $\left[{ }^{3} \mathrm{H}\right] 1$-methyl-4-phenylpyridinium $\left(\mathrm{MPP}^{+}\right)$. A 20minute incubation with $\mathrm{m} \beta \mathrm{cd}$ reduced the total cellular cholesterol content by $40 \%$ to $60 \%$ as compared with that in untreated cells, without altering the content of the other main lipid species. In this condition, OCT2-mediated uptake of $\mathrm{MPP}^{+}$was reduced by $\sim 50 \%$. When cells were coincubated with empty $\mathrm{m} \beta \mathrm{cd}$ and RAMEB, the cholesterol content and OCT2-mediated uptake of
\end{abstract}

$\mathrm{MPP}^{+}$were comparable to those in untreated cells, suggesting that the $\mathrm{m} \beta \mathrm{cd}$ effect on OCT2 activity was cholesterol dependent. In untreated cells, the $\mathrm{MPP}^{+}$influx kinetics was allosteric, whereas in cells treated with $\mathrm{m} \beta \mathrm{cd}$, one binding site was observed. Our findings suggest that changes in cellular cholesterol content can dramatically alter OCT2-mediated transport, potentially resulting in abnormal tubular secretion and unexpected drug toxicity and drug-drug interactions.

\section{SIGNIFICANCE STATEMENT}

Plasma membrane cholesterol is important for the allosteric properties of OCT2. From a pharmacologic standpoint, the variability in cholesterol content stemming from certain pathophysiologic conditions such as aging and acute kidney injury should be taken into account as additional source of interpatient pharmacokinetic/pharmacodynamic variability and unexpected toxicity profile of OCT2 substrates, which can escape preclinical and clinical development.

\section{Introduction}

The human organic cation transporter 2 (OCT2) is a $\mathrm{Na}^{+}-$ independent, polyspecific cation transporter primarily located at the basolateral plasma membrane of renal proximal tubule cells. It mediates the first step of tubular secretion by translocating various substrates from the interstitium (blood side) into the proximal tubule cells. Substrates of OCT2 are several endogenous compounds, such as choline and its metabolite trimethylamine $N$-oxide, various neurotransmitters, widely used drugs such as cimetidine, oxaliplatin, cisplatin, gentamicin, and metformin, and fluorinated choline (fluorocholine), which is routinely used in positron emission tomography

This work was supported by the Swiss National Science Foundation [Grant 310030_175639] (to G.A.K.-U.)

https://doi.org/10.1124/jpet.119.260877. imaging of malignancies such as brain and prostate cancer (Koepsell, 2013; Gai et al., 2016; Visentin et al., 2017, 2018). The pivotal role of OCT2 in renal excretion of drugs is underscored by the guidances of drug regulatory agencies, which demand that each molecule in development be tested in vitro for inhibition of OCT2 transport activity to predict potential drug-drug interactions (http://www.ema.europa.eu/ docs/en_GB/document_library/Scientific_guideline/2012/07/ WC500129606.pdf; http://www.fda.gov/downloads/Drugs/ GuidanceComplianceRegulatoryInformation/Guidances/ UCM292362.pdf).

As an integral membrane protein with 12 predicted transmembrane domains spanning the lipid bilayer, OCT2 is embedded in the plasma membrane, in contiguity with the variety of lipid components of the surrounding microenvironment. In particular, plasma membrane cholesterol is a critical

ABBREVIATIONS: CHO, Chinese hamster ovary; DMEM, Dulbecco's modified Eagle's medium; DMPG, 1,2-dimyristoyl-sn-glycero-3-phospho(1-rac-glycerol); DPPC, 1,2-dipalmitoyl-sn-glycero-3-phosphocholine; DTT, dithiothreitol; HEK293, human embryonic kidney 293 cells; m $\beta$ cd, methyl$\beta$-cyclodextrin; $\mathrm{MPP}^{+}, \mathrm{N}$-methyl-4-phenylpyridinium acetate; MRP2, multidrug resistance-associated protein 2; OCT, organic cation transporter; POPC, 1-palmitoyl-2-oleoyl-sn-glycero-3-phosphocholine; RAMEB, cholesterol-presaturated $\mathrm{m} \beta \mathrm{cd}$; TEA, tetraethanolamine bromide; TLC, thin layer chromatography; WT, wild type. 
regulator of the activity of several transport proteins as well as signaling pathway receptors (Scanlon et al., 2001; Ringerike et al., 2002; Caliceti et al., 2012; Dickens et al., 2017). First, by interacting with phospholipids, cholesterol regulates the fluidity of the lipid bilayer, which can dictate the mobility of the carrier and, in turn, its binding to the substrate as well as its cycling (Cooper, 1978; Chong, 1994; Radhakrishnan and McConnell, 1999; Radhakrishnan et al., 2000; Huang, 2002; Andersen and Koeppe, 2007). Additionally, cholesterol can directly interact with transmembrane proteins at the level of cholesterol recognition/interaction amino acid consensus sequences (CRAC and CARC) or areas flanking a GXXXG sequence (Fantini and Barrantes, 2013).

The plasma membrane cholesterol content of the proximal tubule cells, similar to that of other tissues, is highly dynamic and subject to substantial changes under both physiologic and pathologic conditions. For instance, the cholesterol-to-phospholipid ratio increases up to $25 \%$ during senescence in rat kidney membranes (Grinna, 1977; Hegner, 1980; Pratz and Corman, 1985). Additionally, mice with acute kidney injury display a substantial (up to 50\%) increase in the total membrane cholesterol level, depending on the underlying injury model (ischemia/reperfusion or obstructive nephropathy) (Zager et al., 1999).

These fluctuations in membrane cholesterol content may influence the process of tubular secretion. For instance, it has been previously shown that the transport of the organic cation tetraethanolamine bromide (TEA) in brush-border membrane vesicles is elevated by cholesterol enrichment (Nabekura et al., 1996). Our present work studies the effect of the chemical depletion of cholesterol on OCT2 activity in intact cells overexpressing human OCT2.

\section{Materials and Methods}

Reagents. $N$-methyl-4-phenylpyridinium, acetate $\left[N\right.$-methyl- $\left.{ }^{3} \mathrm{H}\right]-$ $N$-methyl-4-phenylpyridinium $\left(\left[{ }^{3} \mathrm{H}\right] \mathrm{MPP}^{+}\right.$, specific activity: $81.3 \mathrm{Ci} /$ $\mathrm{mmol})$, and cholesterol $\left[4-{ }^{14} \mathrm{C}\right]$-cholesterol $\left(\left[{ }^{14} \mathrm{C}\right]\right.$ cholesterol, specific activity: $50.8 \mathrm{mCi} / \mathrm{mmol}$ ) were purchased from PerkinElmer (Boston, MA). Nonlabeled $\mathrm{MPP}^{+}$, methyl- $\beta$-cyclodextrin $(\mathrm{m} \beta \mathrm{cd})$, cholesterol, sphingomyelin, phosphatidylcholine, phosphatidylserine, phosphatidylinositol, and phosphatidylethanolamine were provided by Sigma-Aldrich (St. Louis, MO). Cholesterol-presaturated $\mathrm{m} \beta \mathrm{cd}$ (RAMEB) was provided by CycloLab Ltd. (Budapest, Hungary). Penicillin/streptomycin mixtures, Geneticin G-418, and Dulbecco's modified Eagle's medium (DMEM) culture medium were purchased from ThermoFisher Scientific (Waltham, MA). Biowest fetal bovine serum was provided by VWR (Dietikon, CH). Poly-D-lysine was purchased from Corning (Bedford, MA).

Cell Lines. Wild-type human embryonic kidney 293 cells (WTHEK293) were maintained in DMEM supplemented with $10 \%$ FBS, $100 \mathrm{U} / \mathrm{ml}$ penicillin, and $100 \mu \mathrm{g} / \mathrm{ml}$ streptomycin at $37^{\circ} \mathrm{C}$ in a humidified atmosphere of $5 \% \mathrm{CO}_{2}$. Cells stably expressing the pcDNA3.1(+) plasmid containing the untagged coding sequence of the human OCT2 (OCT2-HEK293) were grown under selective pressure with Geneticin G-418 at the extracellular concentration of $400 \mu \mathrm{g} / \mathrm{ml}$ (Thévenod et al., 2013).

Plasma Membrane Integrity Assay. To assess cell membrane integrity, WT-HEK293 cells were seeded on 12-well plates coated with $0.1 \mathrm{mg} / \mathrm{ml}$ poly-D-lysine at a density of $2 \times 10^{5}$ cells/well. After 48 hours the cells were washed, treated for 20 minutes at $37^{\circ} \mathrm{C}$ with $\mathrm{m} \beta \mathrm{cd}$ dissolved in transport buffer (116.4 mM NaCl, $5.3 \mathrm{mM} \mathrm{KCl}, 1 \mathrm{mM}$ $\mathrm{NaH}_{2} \mathrm{PO}_{4}, 0.8 \mathrm{mM} \mathrm{MgSO}$, $5.5 \mathrm{mM}$ D-glucose, and $20 \mathrm{mM}$ HEPES/ $\mathrm{KOH}, \mathrm{pH} 7.4)$, then washed with PBS and finally resuspended in a $0.02 \%$ Trypan blue solution for cell counting.
Immunofluorescence of OCT2-HEK293 Cells. The cells were seeded on chamber slides at a density of $4 \times 10^{4}$ cells per chamber, coated with $0.1 \mathrm{mg} / \mathrm{ml}$ poly-D-lysine. Seventy-two hours later, the cells were washed with cold PBS, fixed in $4 \%$ paraformaldehyde, and treated with $0.1 \%$ Triton X-100 in PBS for 15 minutes and with $0.1 \%$ Tween- 20 in $1 \%$ bovine serum albumin/PBS for 30 minutes. The cells were then incubated at $4^{\circ} \mathrm{C}$ overnight with an antibody raised against the full-length OCT2 protein (Clone \#640438; R\&D Systems, Minneapolis, MN). After washing, the cells were mounted with 4',6diamidino-2-phenylindole (Vector Laboratories, Burlingame, CA) and visualized under a fluorescent microscope (DMI6000B; Leica Microsystems, Wetzlar, Germany).

Lipid Extraction. Lipid extraction was performed with a standard chloroform/methanol method (Folch et al., 1951). The cells were seeded at a density of $0.5-1 \times 10^{6}$ cells per dish on $10-\mathrm{cm}$ dishes precoated with $0.1 \mathrm{mg} / \mathrm{ml}$ of poly-D-lysine. After 72 hours, the cells were gently scraped from the plate and spun down for 5 minutes at $900 g_{\text {av }}$. The pellet was resuspended in $1 \mathrm{ml}$ of PBS. One hundred microliters were lysed with $900 \mu \mathrm{l}$ of $0.1 \%$ (w/v) Triton X-100 in deionized water for bicinchoninic acid protein determination.

The remaining cell suspension was mixed with $3 \mathrm{ml}$ of chloroform: methanol (2:1) solution spiked with ${ }^{14} \mathrm{C}$-cholesterol, serving as an internal standard. The amount of ${ }^{14} \mathrm{C}$-cholesterol added as the internal standard did not exceed $1 \%$ of the total cholesterol content measured in untreated cells. After 20 minutes of shaking, samples were centrifuged for 5 minutes at $3000 g_{\text {av }}$ for phase separation. The lower phase containing the lipid fraction was dried under a faint nitrogen flux at $30^{\circ} \mathrm{C}$. Finally, the lipid pellet was resuspended in $600 \mu \mathrm{l}$ of ice-cold chloroform. A 50- $\mu \mathrm{l}$ aliquot was used for assessing radioactivity by liquid scintillation counting.

Thin Layer Chromatography. For analysis of the cholesterol and phospholipid content, aliquots from the extracted lipids were loaded on high-performance thin layer chromatography (HPTLC) Silica Gel 60 plates with a concentrating zone (Merck KGaA, Darmstadt, Germany) using an automated Camag thin layer chromatography (TLC) sampler ATS4 and separated by one-dimensional TLC. Cholesterol was resolved in $62.3 \%$ n-hexane, $18.3 \%$ n-heptane, $18.4 \%$ diethyl ether, and $1 \%$ acetic acid. Phospholipids were resolved in $26.6 \%$ methyl acetate (v/v), 26.6\% 1-propanol (v/v), 26.6\% chloroform $(\mathrm{v} / \mathrm{v}), 10.6 \%$ methanol $(\mathrm{v} / \mathrm{v})$, and $0.05 \% \mathrm{KCl}(\mathrm{w} / \mathrm{v})$. Staining was performed in $9.6 \%$ ortho phosphoric acid (v/v) and $3 \%$ copper acetate $(\mathrm{w} / \mathrm{v})$, and then the plate was dried at $120^{\circ} \mathrm{C}$ for 30 minutes.

The bands were scanned at $366 \mathrm{~nm}$, and absolute quantification performed from a serial dilution of the main lipid species separated in parallel. The values were then normalized for the $\left[{ }^{14} \mathrm{C}\right]$ cholesterol recovery yield and the protein content.

Cell Surface Labeling. Nearly confluent OCT2-HEK293 cells were washed twice with PBS and treated with $1 \mathrm{mg} / \mathrm{ml}$ of EZ-Link Sulfo-NHS-LC-biotin in PBS on ice for 1 hour. This nonpermeable reagent alkylates the accessible Lys residues. The cells were then washed twice and incubated for 30 minutes with hypotonic buffer $\left(0.5 \mathrm{mM} \mathrm{Na}_{2} \mathrm{HPO}_{4}\right.$ and $0.1 \mathrm{mM}$ EDTA at $\left.\mathrm{pH} 7.0\right)$ containing protease inhibitors. The cells were then scraped from the plates and centrifuged at $16,000 g_{\text {av }}$ for 15 minutes at $4^{\circ} \mathrm{C}$. The pellet was lysed in $200 \mu \mathrm{l}$ of lysis buffer (0.1\% SDS, $1 \%$ Triton X-100, $1 \mathrm{mM}$ EDTA, $150 \mathrm{mM} \mathrm{NaCl}$, and $20 \mathrm{mM}$ Tris, $\mathrm{pH}$ 7.4) containing protease inhibitors and rotated for 2 hours at $4^{\circ} \mathrm{C}$, then spun down at $16,000 g_{\text {av }}$ at $4^{\circ} \mathrm{C}$ for 15 minutes.

A portion of the supernatant was used for bicinchoninic acid protein determination and for total lysate analysis. The remaining portion was mixed with streptavidin-agarose beads ( $50 \mu \mathrm{l} /$ sample) overnight at $4^{\circ} \mathrm{C}$. The beads were washed twice in lysis buffer and twice in lysis buffer supplemented with $2 \%$ (w/v) SDS. After the final wash, the bead-bound proteins were stripped; the samples were incubated at $95^{\circ}$ $\mathrm{C}$ for 5 minutes in Laemmli buffer containing 1.5\% (w/v) dithiothreitol (DTT) and loaded directly onto polyacrylamide gels. The total lysate samples were denaturated using the same conditions.

SDS Gel Electrophoresis and Western Blotting. Surface labeling protein samples and the respective total lysates were resolved 
on $8 \%(\mathrm{w} / \mathrm{v})$ polyacrylamide gels. To assess the OCT2 oligomerization state, total lysate samples were denatured for 15 minutes at $50^{\circ} \mathrm{C}$ in Laemmli buffer with or without $1.5 \% \mathrm{DTT}(\mathrm{w} / \mathrm{v})$, then were resolved on a gel with a $6 \%$ to $12 \%(\mathrm{w} / \mathrm{v})$ gradient of polyacrylamide. Proteins were electroblotted onto nitrocellulose membranes (GE Healthcare, Piscataway, NJ). The membranes were blocked with $5 \%(\mathrm{w} / \mathrm{v})$ nonfat dry milk in PBS supplemented with $0.1 \%(\mathrm{w} / \mathrm{v})$ Tween-20 and were incubated overnight at $4^{\circ} \mathrm{C}$ with anti-OCT2 (Clone \#640438; R\&D Systems), followed by probing with a horseradish peroxidaseconjugated secondary antibody. Blots were developed with SuperSignal West Femto Maximum Sensitivity Substrate (Thermo Scientific) and Fusion FX7 (Vilber Lourmat, Eberhardzell, Germany). As a control, the sample blots were probed with anti-pan-actin.

Transport Studies in Intact Cells. Uptake of radiolabeled compounds was measured using a protocol designed for uptake determination in cells (Schroeder et al., 1998; Visentin et al., 2015). WTHEK293 and OCT2-HEK293 cells were seeded at a density of $2.5 \times 10^{5}$ cells/dish on $35-\mathrm{mm}$ dishes coated with $0.1 \mathrm{mg} / \mathrm{ml}$ poly-D-lysine (Corning). After 72 hours, the cells were washed and equilibrated in transport buffer (116.4 mM NaCl, $5.3 \mathrm{mM} \mathrm{KCl,} 1 \mathrm{mM} \mathrm{NaH}_{2} \mathrm{PO}_{4}, 0.8 \mathrm{mM} \mathrm{MgSO}_{4}$, $5.5 \mathrm{mM}$ D-glucose, and $20 \mathrm{mM}$ HEPES/KOH, $\mathrm{pH} 7.4$ ) at $37^{\circ} \mathrm{C}$, then the buffer was aspirated and transport buffer containing the radiolabeled substrate was added. Uptake was stopped by quick aspiration followed by extensive washing with ice-cold transport buffer.

The cells were solubilized and the intracellular radioactivity was assessed by liquid scintillation counting. Protein content was determined by the bicinchoninic acid protein assay (Interchim, Montluçon, France). OCT2-independent uptake was determined in WT-HEK293 cells and subtracted from the total uptake to quantify the OCT2mediated transport. Uptake is expressed as picomoles of substrate per milligram of protein.

Statistical Analysis. Statistical comparisons were performed using GraphPad Prism (version 5.0 for Windows; GraphPad Software, San Diego, CA). Comparisons between two groups were performed with the two-tailed Student's unpaired $t$ test. For multiple comparisons, oneway ANOVA followed by Bonferroni's post hoc test was employed.

\section{Results}

Acute Exposure to $\mathbf{m} \beta \mathrm{cd}$ Removed Cholesterol without Changing the Content of the Other Major Classes of Lipids nor Affecting Cell Membrane Integrity. Cyclodextrins are torus-shaped cyclic oligosaccharides with a hydrophobic inner cavity that attracts and encapsulates nonpolar substances in close proximity. Among cyclodextrin molecules, methyl- $\beta$-cyclodextrin $(\mathrm{m} \beta \mathrm{cd})$ preferentially accepts and scavenges cholesterol (Zidovetzki and Levitan, 2007). WTHEK293 cells exposed to $\mathrm{m} \beta \mathrm{cd}$ for 20 minutes showed a dosedependent cholesterol depletion (Fig. 1A). At the highest extracellular concentration of $\mathrm{m} \beta \mathrm{cd}$ tested, the total cholesterol content of WT- and OCT2-HEK293 cells was reduced by $\sim 60 \%$ and $40 \%$ respectively, as compared with the respective untreated cells (Fig. 1B).

Because most of the cellular cholesterol resides within the plasma membrane, it can be assumed that total cholesterol content reflects that of the plasma membrane (Lange et al., 1989). Because cholesterol has a time- and concentrationdependent effect on membrane organization and permeability (Raffy and Teissie, 1999), the effect of $\mathrm{m} \beta \mathrm{cd}$-induced cholesterol depletion on membrane permeability was also assessed.

WT-and OCT2-HEK293 cells were exposed for 20 minutes to increasing extracellular concentrations of $\mathrm{m} \beta \mathrm{cd}$ and then mixed with Trypan blue solution for cell counting. Figure 1C shows that the majority of cells were impermeable to Trypan blue, suggesting preserved membrane integrity. Although $\mathrm{m} \beta \mathrm{cd}$ is considered relatively specific for cholesterol, some studies have reported the depletion of other lipids as well (Ottico et al., 2003; Giocondi et al., 2004; Monnaert et al., 2004). After a 20-minute incubation of WT- and OCT2HEK293 cells with $\mathrm{m} \beta \mathrm{cd}$ at an extracellular concentration of $10 \mathrm{mM}$, no obvious depletion of the other major classes of lipids was observed (Fig. 2).

Mßcd Exposure Impaired MPP ${ }^{+}$Influx Mediated by OCT2. Figure 3A illustrates the time course of $\mathrm{MPP}^{+}$uptake over 15 minutes at an extracellular concentration of $0.5 \mu \mathrm{M}$ at pH 7.4 in WT- and OCT2-HEK293 cells. The increase in intracellular $\mathrm{MPP}^{+}$rapidly deviated from linearity, reaching equilibrium within 5 minutes. The time course over a shorter interval showed that $\mathrm{MPP}^{+}$uptake as a function of time was linear over 15 seconds, reflecting the unidirectional flux of $\mathrm{MPP}^{+}$ into the cells. The transport rate of $\mathrm{MPP}^{+}$in OCT2-HEK293 cells was $\sim 36$ times higher than that in the WT-HEK293 cells (slope, $0.36 \pm 0.01$ vs. $0.01 \pm 0.02 \mathrm{pmol} \mathrm{mg}^{-1} \mathrm{~s}^{-1}$ ) (Fig. 3B).

Based on the time course, the effect of a 20-minute preincubation with $\mathrm{m} \beta$ cd on OCT2-mediated $\mathrm{MPP}^{+}$transport was assessed over a 5-second interval at an $\mathrm{MPP}^{+}$extracellular concentration of $0.5 \mu \mathrm{M}$. In Fig. $3 \mathrm{C}$, it can be seen that
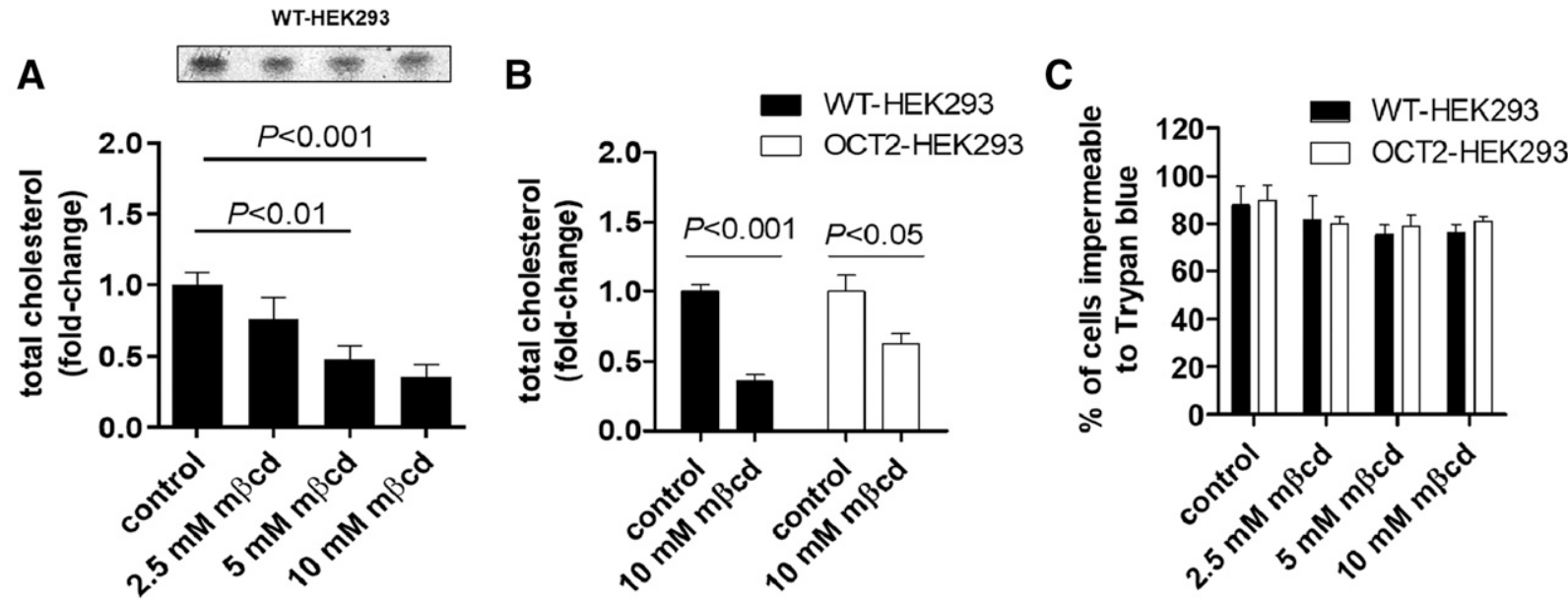

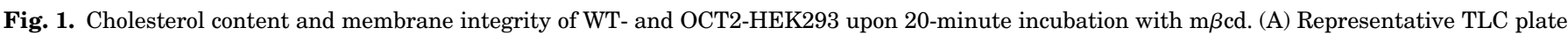

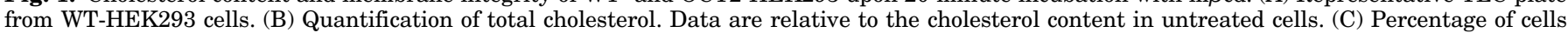
impermeable to Trypan Blue dye. All results represent the mean \pm S.D. from three independent experiments. 
A

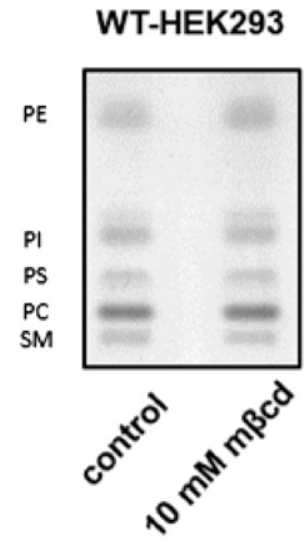

D

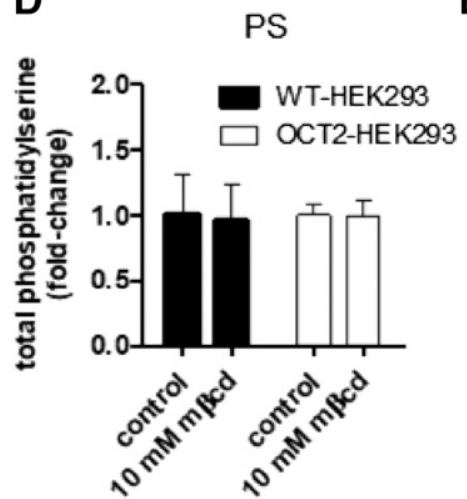

B

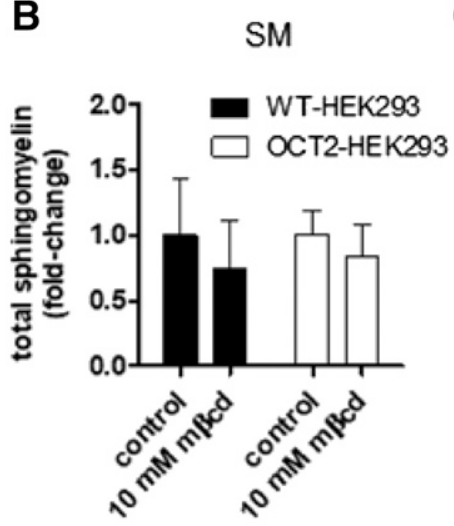

$\mathbf{E}$

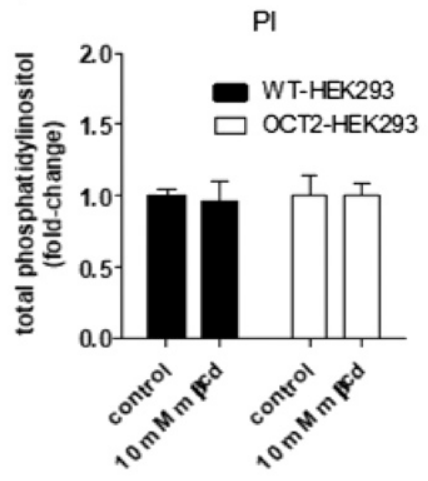

C

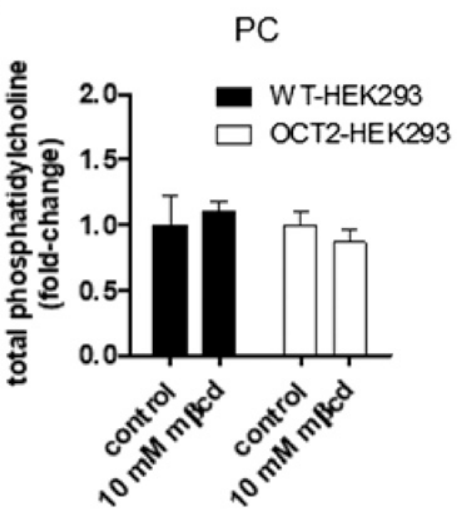

$\mathbf{F}$

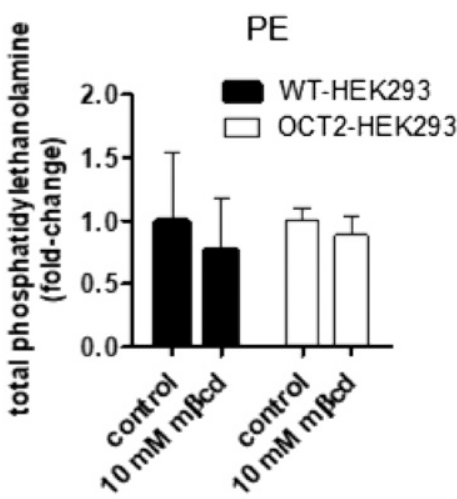

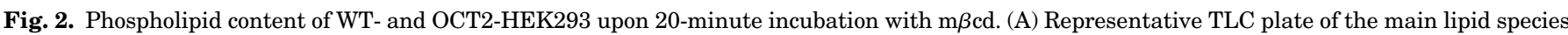

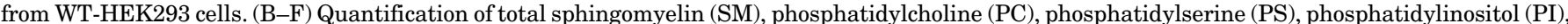

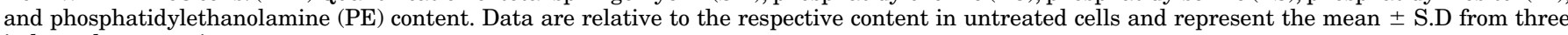
independent experiments.

$\mathrm{MPP}^{+}$influx was significantly lower in the $\mathrm{m} \beta \mathrm{cd}$-treated cells in comparison with that in the untreated cells $(36.4 \pm 5.9 \mathrm{vs}$. $22.2 \pm 3.3 \mathrm{pmol} \mathrm{mg}^{-1}$ minute $^{-1}$ ).

To rule out any direct effect of $\mathrm{m} \beta c \mathrm{~cd}$ on OCT2, a cisinhibition assay was performed. Figure $3 \mathrm{D}$ shows that $\mathrm{m} \beta \mathrm{cd}$ coincubation had no effect on $\mathrm{MPP}^{+}$OCT2-mediated influx $\left(100.0 \pm 14.9\right.$ vs. $110.8 \pm 36.9 \mathrm{pmol} \mathrm{mg}^{-1}$ minute $\left.^{-1}\right)$. For the cis-inhibition control, the cells were exposed to nonlabeled $\mathrm{MPP}^{+}$at an extracellular concentration of $1 \mathrm{mM}$.

Incubation with mßcd-RAMEB Mixture Did Not Alter Total Cholesterol Levels and OCT2-Mediated MPP $^{+}$Influx. $\mathrm{M} \beta$ cd may have multiple nonspecific effects in addition to cholesterol depletion (Ormerod et al., 2012). To assess whether the effect of $\mathrm{m} \beta \mathrm{cd}$ on OCT2-mediated $\mathrm{MPP}^{+}$influx was indeed the result of cholesterol depletion, "cholesterol-matched" experiments were performed. To determine the cholesterol equilibrium point, different ratios of empty $\mathrm{m} \beta \mathrm{cd}$ and RAMEB were tested in WT- and OCT2HEK293 cells.

It can be seen that cells exposed for 20 minutes to a 1 : $1 \mathrm{~m} \beta c \mathrm{c}$ :RAMEB mixture showed similar total cholesterol content to that of control cells (Fig. 4, A and B). Figure 4C shows that the $\mathrm{MPP}^{+}$influx mediated by OCT2 in cells exposed to $1: 1 \mathrm{~m} \beta \mathrm{cd} / \mathrm{RAMEB}$ was comparable to that in control cells, suggesting that the transport of $\mathrm{MPP}^{+}$was reduced only when membrane cholesterol was depleted.

Mßcd Did Not Alter Cell Surface Expression of OCT2. The impact of cellular cholesterol manipulation on OCT2 protein levels and localization was assessed by Western blotting of the plasma membrane OCT2, pulled down by lysine residue labeling (Fig. 5A) and by immunofluorescence and (Fig. 5B). It can be seen that the treatment with $\mathrm{m} \beta \mathrm{cd}$ at an extracellular concentration of $10 \mathrm{mM}$ did not appear to affect the surface expression of OCT2. The selective labeling of the plasma membrane protein fraction was confirmed by the negative probing for actin (Fig. 5A).

Mßcd Exposure Did Not Affect OCT2 Oligomerization State. It has previously been shown that OCT2 exists in monomeric and oligomeric states and that disruption of oligomerization by DTT exposure or mutagenesis of specific cysteine residues reduced the OCT2 transport rate (Brast et al., 2012). The oligomerization state of OCT2 after $\mathrm{m} \beta \mathrm{cd}$ treatment was assessed by Western blotting under nonreducing conditions. In Fig. $5 \mathrm{C}$ it can be seen that most OCT2 appears to be in the monomer state and a weaker band is observed at the size compatible with a tetramer, although the presence of heterocomplex cannot be excluded. No obvious change that could explain the dramatic effect of $\mathrm{m} \beta \mathrm{cd}$ on OCT2-mediated $\mathrm{MPP}^{+}$influx kinetics could be discerned.

Incubation with $\mathbf{m} \beta \mathrm{cd}$ Shifted OCT2-Mediated MPP ${ }^{+}$ Influx Kinetics from Sigmoidal to Hyperbolic. The kinetic basis underlying the reduced $\mathrm{MPP}^{+}$influx upon cholesterol removal was assessed by measuring the OCT2mediated influx (5 seconds) of $\mathrm{MPP}^{+}$as a function of the extracellular concentration of substrate after a 20-minute preincubation with $\mathrm{m} \beta \mathrm{cd}$ at an extracellular concentration of $10 \mathrm{mM}$. Figure 6, A-C, shows a sigmoidal and a hyperbolic 
A

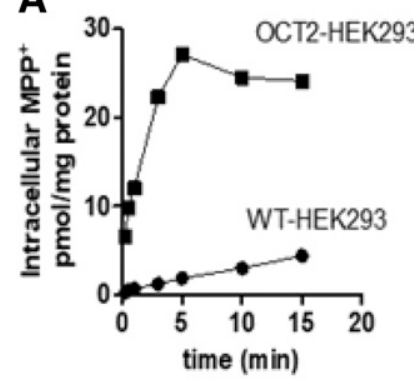

C

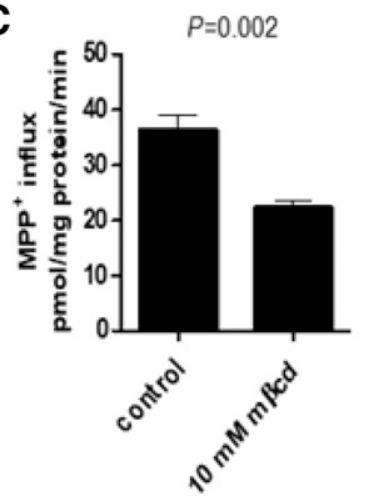

B

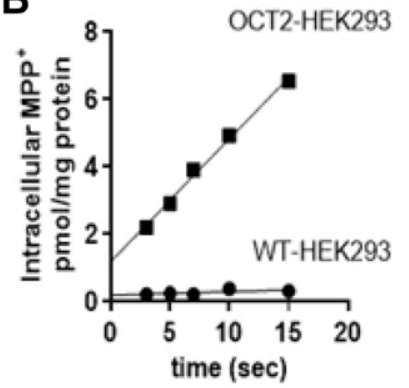

D

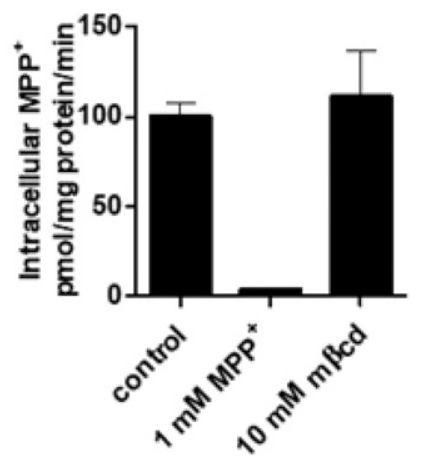

Fig. 3. OCT2-mediated $\mathrm{MPP}^{+}$transport. (A and B) Time course of $\mathrm{MPP}^{+}$ at the extracellular concentrations of $0.5 \mu \mathrm{M}$ in WT- and OCT2-HEK293 cells. Representative of two independent experiments. (C) OCT2-mediated $\mathrm{MPP}^{+}$influx at the extracellular concentrations of $0.5 \mu \mathrm{M}$ after 20 -minute incubation with $\mathrm{m} \beta \mathrm{cd}$. Data were corrected for uptake in WT-HEK293 cells and represent the mean \pm S.D. from three independent experiments. (D) OCT2-mediated $\mathrm{MPP}^{+}$influx rate at the extracellular concentration of $1 \mu \mathrm{M}$ in the presence of $\mathrm{m} \beta \mathrm{cd}$. Coincubation with nonlabeled $\mathrm{MPP}^{+}$ was used as positive control. Uptake values in WT-HEK293 were subtracted and results expressed as the mean \pm S.D. from three independent experiments.

curve of $\mathrm{MPP}^{+}$OCT2-mediated influx in control and $\mathrm{m} \beta \mathrm{cd}-$ treated cells, respectively, suggesting that the removal of cholesterol abolished the allosteric binding of $\mathrm{MPP}^{+}$to OCT2. The switch from homotropic positive cooperativity to one-binding

site kinetics was confirmed by the Eadie-Hofstee and Hill linear transformations (Fig. 6, D-F; Table 1).

\section{Discussion}

OCT2-mediated influx kinetics that deviate from the classic hyperbole (one binding site kinetics) to the sigmoid with two cooperative binding sites are not surprising and were previously shown for gentamicin and choline by our group (Gai et al., 2016; Visentin et al., 2018). Moreover, the presence of multiple interacting binding sites has been described studying rat OCT1, whose protein sequence is $69 \%$ identical to that of human OCT2 (Gorbunov et al., 2008; Minuesa et al., 2009, 2017). Nonetheless, for the very same substrates, one binding site kinetics for the human OCT2 have been reported as well. These discordant results may stem from the varying in vitro models used in these studies: OCT2-mediated influx has been described as the classic hyperbola consistent with the Michaelis-Menten model in Xenopus laevis oocytes and in Chinese hamster ovary (CHO) cells, and as sigmoid in HEK293 cells (Gorboulev et al., 1997; Budiman et al., 2000; Gai et al., 2016; Severance et al., 2017; Visentin et al., 2018).

Here we show that after cholesterol depletion by exposure to the oligosaccharide $\mathrm{m} \beta \mathrm{cd}, \mathrm{MPP}^{+}$uptake in HEK293 cells overexpressing OCT2 loses the allosterism and best fits the Michaelis-Menten equation. Of note, the $\mathrm{MPP}^{+}$influx kinetics in OCT2-HEK293 cells depleted of cholesterol reconcile with previously published data using alternative models, with a calculated OCT2-mediated $\mathrm{MPP}^{+}$influx $K_{\mathrm{m}}$ (Table 1) comparable to those computed from uptake values measured in Xenopus laevis oocytes $(1.2 \mu \mathrm{M})$ or in $\mathrm{CHO}$ cells overexpressing OCT2 $(3.9 \mu \mathrm{M})$ (Gorboulev et al., 1997; Severance et al., 2017).

To clarify the contribution of cholesterol content on the discrepancies observed among experimental models, it will be interesting to perform head-to-head assessments of the lipid content and influx kinetics in different models. Cholesteroldependent allosterism has previously been reported for other

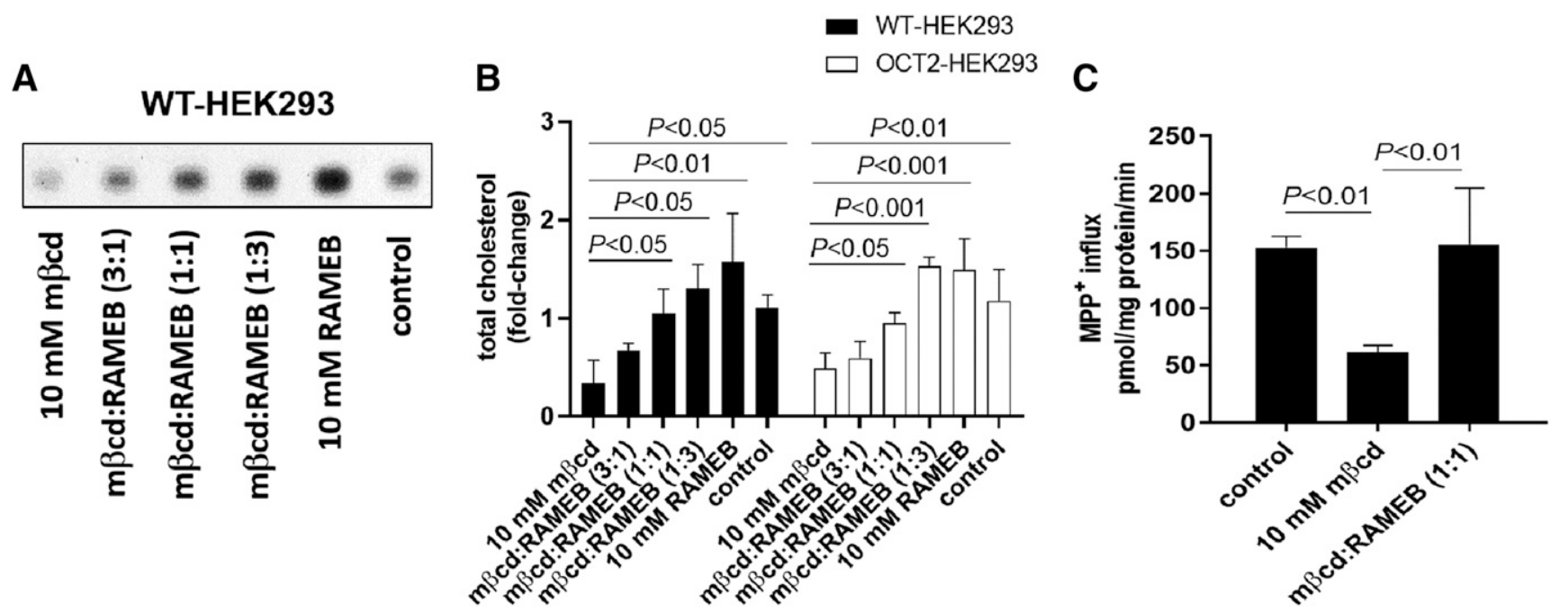

Fig. 4. Cholesterol content and OCT2-mediated $\mathrm{MPP}^{+}$influx after 20 -minute exposure to $\mathrm{m} \beta$ cd-RAMEB mixtures. (A) Representative TLC plate of the cholesterol content in WT-HEK293 cells after incubation with the indicated ratios of $\mathrm{m} \beta \mathrm{cd}$ and RAMEB. (B) Cholesterol content quantification. Data are relative to the cholesterol content in untreated cells and represent the mean \pm S.D from three independent experiments. $(C) \mathrm{Uptake}$ of MPP ${ }^{+}(1 \mu \mathrm{M})$ after 20-minute incubation with $\mathrm{m} \beta \mathrm{cd}$ or 1:1 $\mathrm{m} \beta \mathrm{cd} / \mathrm{RAMEB}$. Data were corrected for uptake in WT-HEK293 cells and represent the mean \pm S.D. from two independent experiments performed in duplicate. 

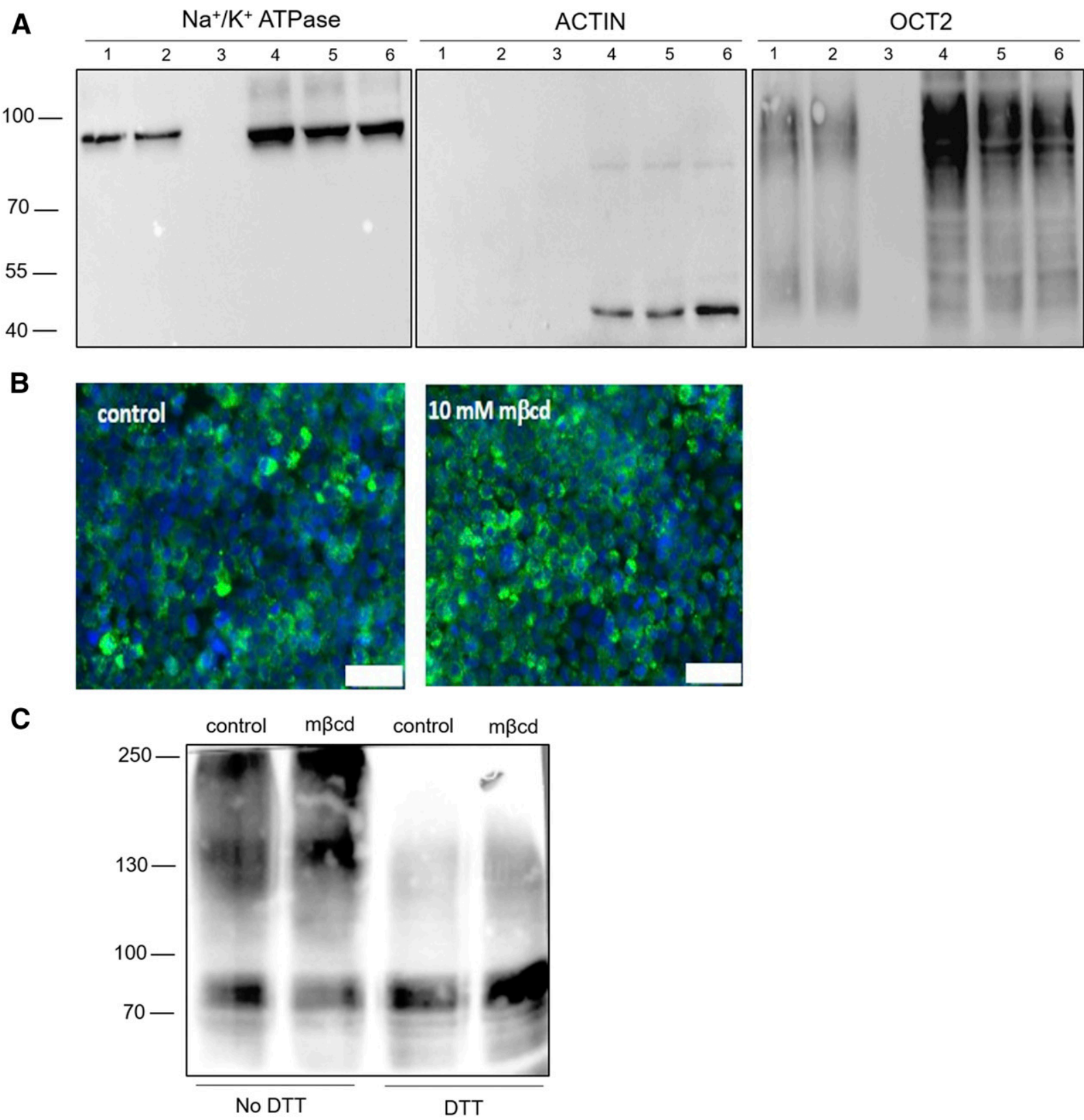

Fig. 5. Western blotting and immunofluorescence of OCT2. Representative Western blots from three independent experiments of OCT2 expression biotinylated at the cell surface $(1,2$, and 3$)$ and in the total lysate $(4,5$, and 6$)$; actin and $\mathrm{Na}^{+} / \mathrm{K}^{+}$controls are shown. Lanes 1 and 4 are loaded with samples from control OCT2-HEK293 cells, lanes 2 and 5 with samples from OCT2-HEK293 cells exposed to $10 \mathrm{mM} \mathrm{m} \beta \mathrm{cd}$ for $20 \mathrm{minutes}$. (A) Samples from OCT2-HEK293 cells incubated without biotinlyation reagent are shown in lanes 3 and 6. (B) Representative immunostaining from three independent experiments of OCT2 after 20-minute incubation with $\mathrm{m} \beta \mathrm{cd}$. Scale bar, $100 \mu \mathrm{m}$. (C) Representative Western blot of cell lysates from OCT2HEK293 treated for 20 minutes with or without $\mathrm{m} \beta \mathrm{cd}$ and then denaturated in the presence or absence of DTT. The experiment was performed 3 times.

transmembrane proteins, including $\mathrm{Mg}^{++}$- and $\mathrm{Na}^{+} / \mathrm{K}^{+}$ATPase, acetylcholinesterase, and the transport of estradiol$17-\beta$-glucuronide by multidrug resistance-associated protein 2 (MRP2) (Bloj et al., 1973a,b; Guyot et al., 2014). Notably, cholesterol can either promote or inhibit allosterism, and the effect seems to be enzyme dependent. Although cholesterol did induce allosterism of OCT2 as well as of $\mathrm{Mg}^{++}$- and $\mathrm{Na}^{+} / \mathrm{K}^{+}$-ATPase, MRP2 and acetylcholinesterase allosteric binding was observed only in the absence of cholesterol (Bloj et al., 1973a; Guyot et al., 2014).

OCT2 has been shown to exist at the plasma membrane in monomeric and oligomeric form (Brast et al., 2012).
Oligomerization is an important determinant of correct localization, function, and regulation of different transporter proteins, and membrane lipid composition can affect the oligomerization state of the transmembrane proteins embedded therein (Mörs et al., 2013; Alguel et al., 2016; Gupta et al., 2017). Because the removal of cholesterol from OCT2-HEK293 cells did not seem to alter the equilibria between the different states of oligomerization observed for this transporter, it is plausible to hypothesize that the allosterism is a feature of OCT2 binding pockets regardless of the oligomerization state.

In line with this, Keller et al. (2019) recently showed that cell-free-expressed rat OCT1 reconstituted in nanodiscs or 

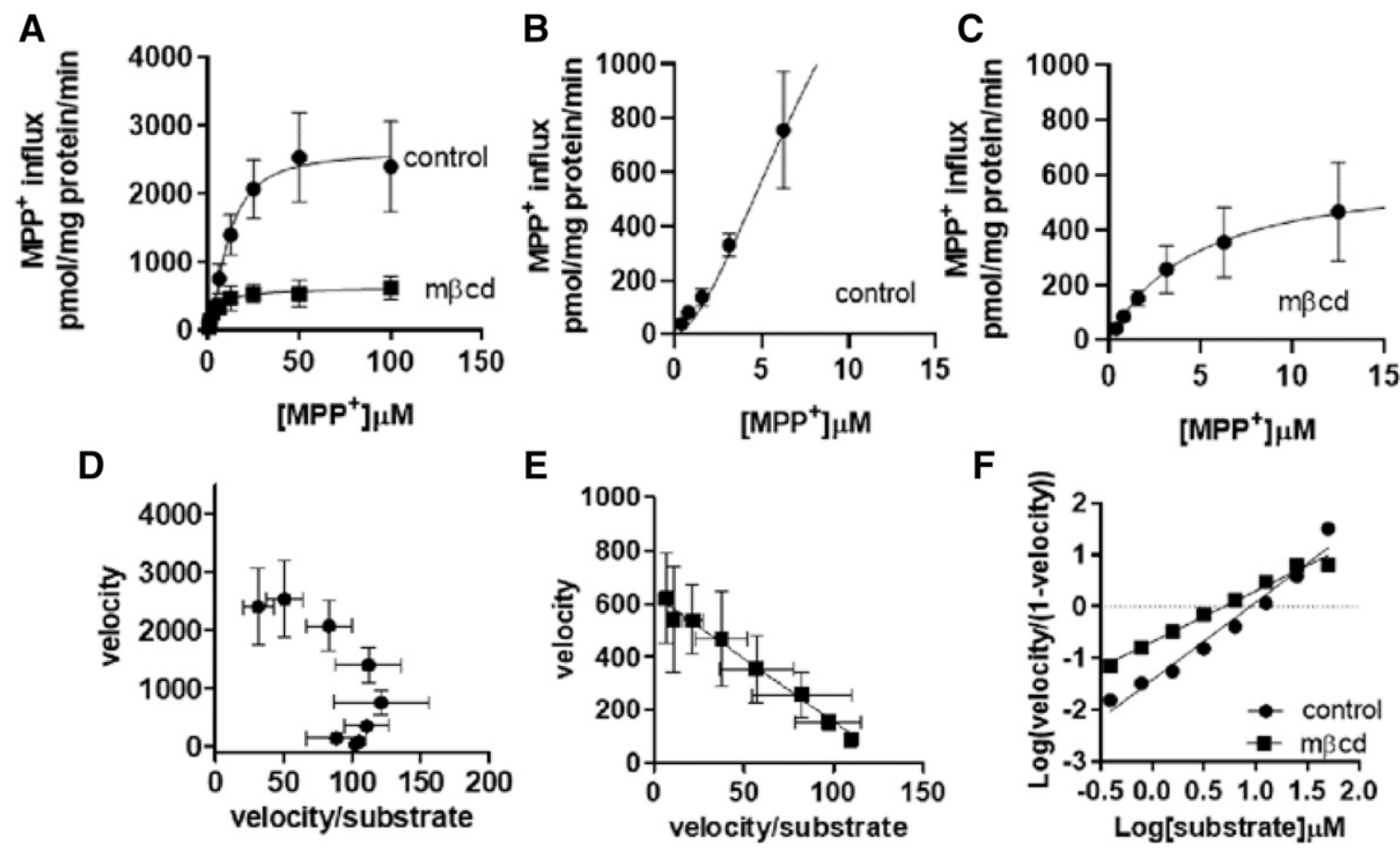

Fig. 6. Kinetic analysis of $\mathrm{MPP}^{+}$influx. Initial uptake of increasing extracellular concentrations of $\mathrm{MPP}^{+}$was assessed over 5 seconds in OCT2HEK293 cells after 20-minute incubation with $\mathrm{m} \beta \mathrm{cd}$. All data were corrected for uptake in WT-HEK293 cells. Line was best fit to an allosteric sigmoidal equation $Y=V_{\max } * X^{\mathrm{h}} /\left(K_{\text {prime }}+X^{\mathrm{h}}\right)$, where $K_{\text {prime }}$ is an estimation of $K_{\mathrm{m}}, V_{\max }$ is the maximum capacity, and h is the Hill slope (A). Enlargement of the first part of OCT2 influx kinetics in (B) control-treated and (C) $\mathrm{m} \beta$ cd-treated cells. Eadie-Hofstee transformation in (D) control and (E) $\mathrm{m} \beta$ cd-treated cells. (F) Hill transformation. Results represent the mean \pm S.D. from four independent experiments.

proteoliposomes displayed one high-affinity binding site and two low-affinity binding sites for $\mathrm{MPP}^{+}$per transporter monomer, with the latter two being responsible for the transport and the first one serving exclusively as an allosteric site. Interestingly, when the binding of the rat OCT1 monomer was assessed in nanodiscs formed with 1,2-dimyristoyl-sn-glycero3-phospho-(1-rac-glycerol) (DMPG) or 1-palmitoyl-2-oleoyl-snglycero-3-phosphocholine (POPC) and 1,2-dipalmitoyl-snglycero-3-phosphocholine (DPPC), only two low-affinity binding sites with overlapping $K_{\mathrm{D}}$ were detected, with the high-affinity binding site not being accessible. However, when the binding was assessed in the presence of 1,2-diacyl-snglycerol-phospho-L-serine, 1,2-diacyl-sn-glycero-3-phosphocholine and cholesterol, three binding sites were detected with three calculated $K_{\mathrm{D}}$ values: $0.1,10$, and $36 \mu \mathrm{M}$, indicating

TABLE 1

Kinetic parameters of $\mathrm{MPP}^{+}$influx mediated by OCT2 after $\mathrm{m} \beta \mathrm{cd}$ treatment

Values are mean \pm S.D.

\begin{tabular}{|c|c|c|c|}
\hline Analysis & $K_{\mathrm{m}}$ & $V_{\max }$ & Hill Slope \\
\hline & $\mu M$ & pmol mg ${ }^{-1}$ minute & \\
\hline \multicolumn{4}{|l|}{ Control } \\
\hline $\begin{array}{l}\text { Nonlinear } \\
\text { regression }\end{array}$ & $46.7 \pm 32.5$ & $2611 \pm 216$ & $1.61 \pm 0.34$ \\
\hline Eadie-Hofstee & - & - & - \\
\hline Hill & - & - & $1.50 \pm 0.11$ \\
\hline \multicolumn{4}{|l|}{$\mathrm{m} \beta \mathrm{cd}$} \\
\hline $\begin{array}{l}\text { Nonlinear } \\
\text { regression }\end{array}$ & $4.75 \pm 2.44$ & $624 \pm 88.3$ & $1.03 \pm 0.41$ \\
\hline Eadie-Hofstee & $4.77 \pm 0.78$ & $632 \pm 43.7$ & - \\
\hline Hill & - & - & $0.98 \pm 0.05$ \\
\hline
\end{tabular}

$\mathrm{m} \beta \mathrm{cd}$, methyl- $\beta$-cyclodextrin; $\mathrm{MPP}^{+}, N$-methyl-4-phenylpyridinium acetate; OCT2, organic cation transporter $2 ; V_{\max }$, maximum capacity; -, not determined. that the lipid composition regulates rat OCT1 allosteric binding (Keller et al., 2019). It is possible that the human OCT2 is equipped with a high-affinity binding site that regulates the allosterism between two low-affinity binding sites as well. However, this needs to be addressed using similar synthetic approaches.

Multispecificity and allosterism are pillars of efficient detoxifying proteins, including transporters (Bodo et al., 2003; Zelcer et al., 2003; Hirono et al., 2005). While multispecificity allows recognizing a broad range of molecules, allosterism confers the ability to adapt to increasing concentrations of substrates. This is evident in Fig. 5: the loss of allosterism upon cholesterol depletion led to a rapid saturation of the OCT2 transport molecules and, in turn, to a limited transport capacity. Because OCT2 plays a key role in the clearance of many drugs and toxins, it is conceivable that pathophysiologic changes in renal membrane cholesterol content may shift the OCT2 kinetics from hyperbolic to sigmoidal, or vice versa.

It has been previously shown that OCT2 expression varies in several pathophysiologic conditions. Rats with acute kidney injury showed lower Oct2 levels (Ji et al., 2002; Matsuzaki et al., 2008; Shim et al., 2009; Maeng et al., 2012). Obesity, both in human and in mice, induces OCT2 expression (Gai et al., 2016). Renal cell carcinoma cells have low OCT2 levels as compared with the surrounding normal tissue (Liu et al., 2016; Visentin et al., 2018). This work adds another level of complexity in the study of OCT2-mediated tubular secretion in renal pathology.

\section{Acknowledgments}

The authors would like to thank Hermann Koepsell, University of Wurzburg, for providing OCT2-HEK293 cells. 


\section{Authorship Contributions}

Participated in research design: Hörmann, Kullak-Ublick,

Visentin

Conducted experiments: Hörmann, Gai, Visentin.

Performed data analysis: Hörmann, Visentin.

Wrote or contributed to the writing of the manuscript: Hörmann, Visentin.

\section{References}

Alguel Y, Cameron AD, Diallinas G, and Byrne B (2016) Transporter oligomerization: form and function. Biochem Soc Trans 44:1737-1744.

Andersen OS and Koeppe RE II (2007) Bilayer thickness and membrane protein function: an energetic perspective. Annu Rev Biophys Biomol Struct 36:107-130.

Bloj B, Morero RD, and Farías RN (1973a) Membrane fluidity, cholesterol and allosteric transitions of membrane-bound $\mathrm{Mg} 2+-\mathrm{ATPase},(\mathrm{Na}++\mathrm{K}+)$-ATPase and acetylcholinesterase from rat erythrocytes. FEBS Lett 38:101-105.

Bloj B, Morero RD, Farías RN, and Trucco RE (1973b) Membrane lipid fatty acids and regulation of membrane-bound enzymes. Allosteric behaviour of erythrocyte $\mathrm{Mg} 2+$-ATPase, $(\mathrm{Na}++\mathrm{K}+)$-ATPase and acetylcholinesterase from rats fed different fat-supplemented diets. Biochim Biophys Acta 311:67-79.

Bodo A, Bakos E, Szeri F, Varadi A, and Sarkadi B (2003) Differential modulation of the human liver conjugate transporters MRP2 and MRP3 by bile acids and organic anions. J Biol Chem 278:23529-23537.

Brast S, Grabner A, Sucic S, Sitte HH, Hermann E, Pavenstädt H, Schlatter E, and Ciarimboli G (2012) The cysteines of the extracellular loop are crucial for trafficking of human organic cation transporter 2 to the plasma membrane and are involved in oligomerization. FASEB $J$ 26:976-986.

Budiman T, Bamberg E, Koepsell H, and Nagel G (2000) Mechanism of electrogenic cation transport by the cloned organic cation transporter 2 from rat. J Biol Chem 275:29413-29420.

Caliceti C, Zambonin L, Prata C, Vieceli Dalla Sega F, Hakim G, Hrelia S, and Fiorentini D (2012) Effect of plasma membrane cholesterol depletion on glucose transport regulation in leukemia cells. PLoS One 7:e41246.

Chong PL (1994) Evidence for regular distribution of sterols in liquid crystalline phosphatidylcholine bilayers. Proc Natl Acad Sci USA 91:10069-10073.

Cooper RA (1978) Influence of increased membrane cholesterol on membrane fluidity and cell function in human red blood cells. J Supramol Struct 8:413-430.

Dickens D, Chiduza GN, Wright GS, Pirmohamed M, Antonyuk SV, and Hasnain SS (2017) Modulation of LAT1 (SLC7A5) transporter activity and stability by membrane cholesterol. Sci Rep 7:43580.

Fantini J and Barrantes FJ (2013) How cholesterol interacts with membrane proteins: an exploration of cholesterol-binding sites including CRAC, CARC, and tilted domains. Front Physiol 4:31.

Folch J, Ascoli I, Lees M, Meath JA, and LeBARON N (1951) Preparation of lipide extracts from brain tissue. J Biol Chem 191:833-841.

Gai Z, Visentin M, Hiller C, Krajnc E, Li T, Zhen J, and Kullak-Ublick GA (2016) Organic cation transporter 2 overexpression may confer an increased risk of gentamicin-induced nephrotoxicity. Antimicrob Agents Chemother 60:5573-5580.

Giocondi MC, Milhiet PE, Dosset P, and Le Grimellec C (2004) Use of cyclodextrin for AFM monitoring of model raft formation. Biophys $J$ 86:861-869.

Gorboulev V, Ulzheimer JC, Akhoundova A, Ulzheimer-Teuber I, Karbach U, Quester S, Baumann C, Lang F, Busch AE, and Koepsell H (1997) Cloning and characterization of two human polyspecific organic cation transporters. DNA Cell Biol 16:871-881.

Gorbunov D, Gorboulev V, Shatskaya N, Mueller T, Bamberg E, Friedrich T, and Koepsell H (2008) High-affinity cation binding to organic cation transporter 1 induces movement of helix 11 and blocks transport after mutations in a modeled interaction domain between two helices. Mol Pharmacol 73:50-61.

Grinna LS (1977) Age related changes in the lipids of the microsomal and the mitochondrial membranes of rat liver and kidney. Mech Ageing Dev 6:197-205.

Gupta K, Donlan JAC, Hopper JTS, Uzdavinys P, Landreh M, Struwe WB, Drew D, Baldwin AJ, Stansfeld PJ, and Robinson CV (2017) The role of interfacial lipids in stabilizing membrane protein oligomers. Nature 541:421-424

Guyot C, Hofstetter L, and Stieger B (2014) Differential effects of membrane cholesterol content on the transport activity of multidrug resistance-associated protein 2 (ABCC2) and of the bile salt export pump (ABCB11). Mol Pharmacol 85:909-920.

Hegner D (1980) Age-dependence of molecular and functional changes in biological membrane properties. Mech Ageing Dev 14:101-118.

Hirono S, Nakagome I, Imai R, Maeda K, Kusuhara H, and Sugiyama Y (2005) Estimation of the three-dimensional pharmacophore of ligands for rat multidrugresistance-associated protein 2 using ligand-based drug design techniques. Pharm Res 22:260-269.

Huang $J$ (2002) Exploration of molecular interactions in cholesterol superlattices: effect of multibody interactions. Biophys $J$ 83:1014-1025

Ji L, Masuda S, Saito H, and Inui K (2002) Down-regulation of rat organic cation transporter rOCT2 by 5/6 nephrectomy. Kidney Int 62:514-524

Keller T, Gorboulev V, Mueller TD, Dötsch V, Bernhard F, and Koepsell H (2019) Rat organic cation transporter 1 contains three binding sites for substrate 1-Methyl-4 phenylpyridinium per monomer. Mol Pharmacol 95:169-182.

Koepsell H (2013) The SLC22 family with transporters of organic cations, anions and zwitterions. Mol Aspects Med 34:413-435.

Lange Y, Swaisgood MH, Ramos BV, and Steck TL (1989) Plasma membranes contain half the phospholipid and $90 \%$ of the cholesterol and sphingomyelin in cultured human fibroblasts. J Biol Chem 264:3786-3793.

Liu Y, Zheng X, Yu Q, Wang H, Tan F, Zhu Q, Yuan L, Jiang H, Yu L, and Zeng S (2016) Epigenetic activation of the drug transporter OCT2 sensitizes renal cell carcinoma to oxaliplatin. Sci Transl Med 8:348ra97.
Maeng HJ, Shim WS, Ahn SJ, Yu SS, Kim DD, Shim CK, and Chung SJ (2012) Differential changes in functional activity of organic cation transporters in rats with uranyl nitrate-induced acute renal failure. Arch Pharm Res 35:1441-1448.

Matsuzaki T, Morisaki T, Sugimoto W, Yokoo K, Sato D, Nonoguchi H, Tomita K, Terada T, Inui K, Hamada A, et al. (2008) Altered pharmacokinetics of cationic drugs caused by down-regulation of renal rat organic cation transporter 2 (Slc22a2) and rat multidrug and toxin extrusion 1 (Slc47a1) in ischemia/reperfusion-induced acute kidney injury. Drug Metab Dispos 36:649-654.

Minuesa G, Albert C, Pastor-Anglada M, Martinez-Picado J, and Koepsell H (2017) Response to "tenofovir disoproxil fumarate is not an inhibitor of human organic cation transporter 1". J Pharmacol Exp Ther 360:343-345.

Minuesa G, Volk C, Molina-Arcas M, Gorboulev V, Erkizia I, Arndt P, Clotet B, Pastor-Anglada M, Koepsell H, and Martinez-Picado J (2009) Transport of lamivudine [(-)-beta-L-2', $3^{\prime}$-dideoxy-3'-thiacytidine] and high-affinity interaction of nucleoside reverse transcriptase inhibitors with human organic cation transporters 1, 2, and 3. J Pharmacol Exp Ther 329:252-261.

Monnaert V, Tilloy S, Bricout H, Fenart L, Cecchelli R, and Monflier E (2004) Behavior of alpha-, beta-, and gamma-cyclodextrins and their derivatives on an in vitro model of blood-brain barrier. J Pharmacol Exp Ther 310:745-751.

Mörs K, Hellmich UA, Basting D, Marchand P, Wurm JP, Haase W, and Glaubitz C (2013) A lipid-dependent link between activity and oligomerization state of the M. tuberculosis SMR protein TBsmr. Biochim Biophys Acta 1828:561-567.

Nabekura T, Takano M, and Inui K (1996) Cholesterol modulates organic cation transport activity and lipid fluidity in rat renal brush-border membranes. Biochim Biophys Acta 1283:232-236.

Ormerod KG, Rogasevskaia TP, Coorssen JR, and Mercier AJ (2012) Cholesterolindependent effects of methyl- $\beta$-cyclodextrin on chemical synapses. PLoS One 7: e36395.

Ottico E, Prinetti A, Prioni S, Giannotta C, Basso L, Chigorno V, and Sonnino S (2003) Dynamics of membrane lipid domains in neuronal cells differentiated in culture. J Lipid Res 44:2142-2151.

Pratz J and Corman B (1985) Age-related changes in enzyme activities, protein content and lipid composition of rat kidney brush-border membrane. Biochim Biophys Acta 814:265-273.

Radhakrishnan A, Anderson TG, and McConnell HM (2000) Condensed complexes, rafts, and the chemical activity of cholesterol in membranes. Proc Natl Acad Sci USA 97:12422-12427.

Radhakrishnan A and McConnell HM (1999) Condensed complexes of cholesterol and phospholipids. Biophys $J$ 77:1507-1517.

Raffy S and Teissié J (1999) Control of lipid membrane stability by cholesterol content. Biophys J 76:2072-2080.

Ringerike T, Blystad FD, Levy FO, Madshus IH, and Stang E (2002) Cholesterol is important in control of EGF receptor kinase activity but EGF receptors are not concentrated in caveolae. J Cell Sci 115:1331-1340.

Scanlon SM, Williams DC, and Schloss P (2001) Membrane cholesterol modulates serotonin transporter activity. Biochemistry 40:10507-10513.

Schroeder A, Eckhardt U, Stieger B, Tynes R, Schteingart CD, Hofmann AF, Meier PJ, and Hagenbuch B (1998) Substrate specificity of the rat liver $\mathrm{Na}(+)$-bile salt cotransporter in Xenopus laevis oocytes and in CHO cells. Am J Physiol 274: G370-G375.

Severance AC, Sandoval PJ, and Wright SH (2017) Correlation between apparent substrate affinity and OCT2 transport turnover. J Pharmacol Exp Ther 362: 405-412.

Shim WS, Park JH, Ahn SJ, Han L, Jin QR, Li H, Choi MK, Kim DD, Chung SJ, and Shim CK (2009) Testosterone-independent down-regulation of Oct2 in the kidney medulla from a uranyl nitrate-induced rat model of acute renal failure: effects on distribution of a model organic cation, tetraethylammonium. J Pharm Sci 98:739-747.

Thévenod F, Ciarimboli G, Leistner M, Wolff NA, Lee WK, Schatz I, Keller T, AlMonajjed R, Gorboulev V, and Koepsell H (2013) Substrate- and cell contactdependent inhibitor affinity of human organic cation transporter 2: studies with two classical organic cation substrates and the novel substrate $\mathrm{cd} 2+$. Mol Pharm 10:3045-3056.

Visentin M, Stieger B, Merz M, and Kullak-Ublick GA (2015) Octreotide inhibits the bilirubin carriers organic anion transporting polypeptides 1B1 and 1B3 and the multidrug resistance-associated protein 2. J Pharmacol Exp Ther 355:145-151.

Visentin M, Torozi A, Gai Z, Häusler S, Li C, Hiller C, Schraml PH, Moch H, and Kullak-Ublick GA (2018) Fluorocholine transport mediated by the organic cation transporter 2 (OCT2, SLC22A2): implication for imaging of kidney tumors. Drug Metab Dispos 46:1129-1136.

Visentin M, van Rosmalen BV, Hiller C, Bieze M, Hofstetter L, Verheij J, KullakUblick GA, Koepsell H, Phoa SS, Tamai I, et al. (2017) Impact of organic cation transporters (OCT-SLC22A) on differential diagnosis of intrahepatic lesions. Drug Metab Dispos 45:166-173.

Zager RA, Burkhart KM, Johnson AC, and Sacks BM (1999) Increased proximal tubular cholesterol content: implications for cell injury and "acquired cytoresistance." Kidney Int 56:1788-1797.

Zelcer N, Huisman MT, Reid G, Wielinga P, Breedveld P, Kuil A, Knipscheer P, Schellens JH, Schinkel AH, and Borst P (2003) Evidence for two interacting ligand binding sites in human multidrug resistance protein 2 (ATP binding cassette C2). $J$ Biol Chem 278:23538-23544

Zidovetzki R and Levitan I (2007) Use of cyclodextrins to manipulate plasma membrane cholesterol content: evidence, misconceptions and control strategies. Biochim Biophys Acta 1768:1311-1324.

Address correspondence to: Dr. Michele Visentin, University Hospital Zurich, Wagistrasse 14, CH-8952 Schlieren, Zurich, Switzerland. E-mail: Michele.visentin@usz.ch 